\title{
Radiology in IUGR: A Study
}

\author{
Som Biswas ${ }^{1 *}$, Srirupa Biswas ${ }^{2}$ \\ ${ }^{I}$ Dept of Radiodiagnosis, GRMC, Gwalior, India \\ ${ }^{2}$ Assistant Professor, School of Pharmacy, ITM University, Gwalior, India
}

"Corresponding Author: Som Biswas, Resident, Dept of Radiodiagnosis, GRMC, Gwalior, India, Email: sombiswas4@gmail.com

\begin{abstract}
Introduction: Every newborn has the right to be born undamaged mentally and physically. The fulfillment of this goal plays a pivotal role in materno-fetal medicine, whose sole objective is that every pregnancy should culminate into a healthy baby and a healthy mother.

Aims and Objectives

$>$ to evaluate the role of colour doppler in assessment of intrauterine fetal growth

$>$ to assess in intrauterine growth retardation

1. uteroplacental circulation which are maternal uterine arteries

2. fetal circulation which includes middle cerebral arteries

$>$ to evaluate the diagnostic accuracy of uterine artery and middle cerebral artery doppler indices as predictors of perinatal outcome in clinically suspected IUGR pregnancies

$>$ to determine the role in its management
\end{abstract}

Material and Method: This study was approved by the Ethical Committee of our institution. Data for the study was collected from patients attending the department of Radiodiagnosis, referred by Department of Obstetric and Gynecology at our college

Summary \& Conclusion: The umbilical-placental and cerebral vascular beds are directly involved in the haemodynamic adjustments of fetal growth restriction. A Doppler index that reflects both of these areas can be useful for identifying fetuses with increased placental and/or decreased cerebral resistance.

Assessment of both the uteroplacental circulation and the fetoplacental circulations together is more sensitive to predict to perinatal outcome, than assessment of each alone.

In suspected IUGR, uterine artery PI proved to be a better predicter in early weeks of pregnancy than uterine artery RI and diastolic notch and umbilical artery and middle cerebral artery.

Best results are obtained when we use MCA PI, which is more sensitive in detecting IUGR in later weeks of geatation from 31-36 weeks rather than umbilical artery and uterine artery And the diagnostic accuracy of the middle cerebral artery is maximum between 31-36 weeks.

Keywords: IUGR, Doppler.

\section{INTRODUCTION}

Every new born has the right to be born undamaged mentally and physically. The fulfillment of this goal plays a pivotal role in materno- fetal medicine, whose sole objective is that every pregnancy should culminate into a healthy baby and a healthy mother. The growth of human fetus, a complex process resulting in an increase in size over time has been the subject of extensive study. Before the advent of ultrasound evaluation physicians are interested in the growth process of fetus, the prospective assessment of fetal growth during pregnancy has been limited to measuring the uterine size and guessing the fetal size by palpation and could only look at the infant at delivery and infer at what happened in utero This lead to increasing perinatal mortality and morbidity. 
The very objective of obstetrics was getting defeated. But now, in the era of sophisticated modality of real time ultrasound, antenatal diagnosis of intrauterine growth restriction has become very easy, thus minimizing the future catastrophe.

Intrauterine growth restriction (IUGR) is a term used to describe the condition of a fetus whose size or growth is subnormal. The most common definition of intrauterine growth restriction is that "a fetus is growth restricted if its weight is less than the tenth percentile for its gestational age1.IUGR is classified into two types symmetric or asymmetric. symmteric IUGR is result of early complication in pregnancy and asymmetric IUGR is result of result later in pregnancy. Asymmetric IUGR which is the focus of current study account for $70 \%$ of cases.

The incidence of IUGR in a population where the mothers are generally healthy and well nourished is estimated to be about $3-5 \%$. In a population of women with hypertension or previous growth restricted fetus however the incidence increases to $15-20 \%$ or higher ${ }^{2}$. The incidence of IUGR varies from region to region and even in the same region, it varies in different sub populations. In India, according to recent UNICEF surveys, the incidence of IUGR is $25-30 \%{ }^{3}$ IUGR has many causes, maternal causes include hypertension, collagen vascular disease, renal disease, poor nutrition and drug or alcohol abuse which causes placental insufficiency. Fetal infections such as cytomegalovirus, toxoplasmosis and chromosomal anomalies such as triplody and trisomies 13 and 18 also result in $\mathrm{IUGR}^{4}$. Placental insufficiency in the absence of any maternal cause is called primary placental insufficiency and is common cause of IUGR. Growth retarded fetuses have eight to ten fold increase in perinatal mortality and 50-75\% morbidity compared to appropriately sized fetuses ${ }^{5}$. Those fetuses who have suffered from IUGR were prone to develop still birth, Intrapartum fetal acidosis, Perinatal asphyxia, Meconium aspiration syndrome, Hypoglycemia, Hypocalcemia, Hypothermia and Hypoxic ischemic encephalopathy etc.

Accurate antenatal diagnosis of IUGR by real time ultrasound can reduce the complications and improve the outcome. After the introduction of ultrasound the small fetuses could be identified, however it could not be determined which of these foetuses were at increased risk due to utero placental insufficiency and therefore needed special surveillance. Small fetuses were therefore monitored by non stress test of fetal heart rate and the biophysical profile.

With the introduction of Doppler Ultrasound examination it became possible to assess the uteroplacental blood flow, feto placental blood flow and to assess the fetal blood circulation. The uteroplacental and fetoplacental circulation give information on the placental resistance whereas evaluating the fetal circulation using Doppler ultrasound could non-invasively assess the fetal response to hypoxia. This is become possible to identify those small fetuses that were at increased risk of perinatal morbidity and mortality due to impaired uteroplacental and fetoplacental circulations Umbilical arterial (Umb A) Doppler velocimetry is the most rigorously evaluated tests of fetal well-being ${ }^{6}$ Doppler ultrasound studies of the human fetal circulation have shown that in fetuses with IUGR there is a significant reduction of middle cerebral arterial (MCA) pulsatility index when compared with those in normal fetuses ${ }^{7}$. At Cordocentesis, a significant correlation has been observed between hypoxemia in foetuses with IUGR and an abnormal MCA pulsatility index ${ }^{8}$.recently published meta-analysis has proved that systemic application of Doppler sonography has resulted in 50\% redection of perinatal mortality among high risk pregnancies.

This dissertation titled "Colour Doppler Evaluation of Uterine Artery and middle cerebral artery in intrauterine foetal growth assessment and its Prognostic Significance" focuses on establishing the role of Umbilical artery and Middle cerebral artery Doppler ultrasound in predicting adverse perinatal outcomes in clinically suspected IUGR pregnancies and to determine the role of Doppler velocimetry in clinical management of such pregnancy

\section{AIMS AND OBJECTIVES}

to evaluate the role of colour doppler in assessment of intrauterine fetal growth

to assess in intrauterine growth retardation

1. uteroplacental circulation which are
maternal uterine arteries

2. fetal circulation which includes middle cerebral arteries

to evaluate the diagnostic accuracy of uterine artery and middle cerebral artery doppler indices as predictors of perinatal outcome in clinically suspected IUGR pregnancies 
to determine the role in its management

\section{Material ANd Method}

This study was approved by the Ethical Committee of our institution. Data for the study was collected from patients attending the department of Radiodiagnosis, referred by Department of Obstetric and Gynecology at our college

Study Design: Prospective study

Study Period: September 2013 to September 2014

Work Plane: Department of Radio diagnosis G.R. Medical College \& Jayarogya Hospital, Gwalior.

\section{Inclusion Criteria}

i. All singleton antenatal women (at 24 weeks)

ii. Females with pregnancy confirmed by first trimester ultrasound by CRL OR BPD or with known LMP

\section{Exclusion Criteria}

i. All antenatal women less than 24 weeks

ii. All subjects with history of fetuses with congenital anamolies,multiple pregnancies rupture of membranes, active labour

Study Group: All antenatal women at 24 weeks fulfilling inclusion criteria in department of radiodiagnosis, G.R.Medical College Gwalior For colour Doppler evaluation of intrauterine growth assesment and management

\section{Methodology}

1. Colour Doppler Aloka Machine Ssd4000

2. Aloka Japan Model Prosound Alpha 6

Doppler US evaluation was performed following a detailed clinical history and US biometry. Subject will be considered cases if fetus is diagnosed with intrauterine growth restriction based on grey scale ultrasound and subsequent Doppler ultrasound will be performed Follow up doppler at 30 weeks and at term will be done if clinically indicated to determine a favourable or worsening trend in Doppler Indices. However, only the results of the patients last Doppler ultrasound examination were used for analysis of perinatal outcome

\section{Outcome Criteria}

Doppler results were analyzed for prediction of perinatal outcome.

\section{Perinatal Outcome Variables Included}

1. Birth Weight

2. Perinatal death

3. Emergency Caesarean section for fetal distress

4. Low APGAR score (5 min APGAR score less than 7)

5. Admission to NICU for complications of Low Birth Weight

Pregnancy was considered to have "Adverse outcome" when any of the following complications were present

I. Perinatal death

II. Emergency CS for fetal distress

III. 5 minute APGAR score of less than 7

IV. Admission to NICU for complications of low birth weight.

Pregnancy outcome was considered to be "normal" when the above complications were absent.

The uterine artery RI $>0.7$ and uterine artery PI value $>1.4$ and presence of diastolic notch were considered abnormal.

The UmA Pulsatility index ratios were considered abnormal if the value was above the 95th percentile for the gestational age (UMA PI value>1.45). UMA S/D ratio >3 were considered abnormal.

UMA diastolic flow velocity patterns were seen which showed normal forward diastolic flow velocity pattern and abnormal reduced, absent and reversed diastolic flow velocity pattern. The MCA pulsatility index was considered abnormal if the value was below the 5 th percentile for the gestational age reference value PI $<1.45$ and $\mathrm{S} / \mathrm{D}$ ratio $<3$, according to reference values of $\mathrm{D}$ Gramellini et al. ${ }^{72}$

Of the various Doppler indices, pulsatility index has the smallest measurement error and narrower reference limits. The MCA/Umb A PI ratio (cerebroumbilical ratio) is usually constant during the last 10 weeks of gestation. It is possible to use a single cut off value after 30th week because cerebralumbillical Doppler ratio does not vary significantly between 30th and 40th weeks as reported by Wladimiroff et al 73 who observed a significant differences in cerebroumbilical ratio only between weeks 26 - 
38. After $26^{\text {th }}$ week, the statistical comparison showed no significant differences between the intervals considered.

The MCA PI/ Umb A PI ratio was calculated. In our study a single cutoff value of 1.08 for MCA/Umb A PI ratio (cerebral-umbilical ratio) was used, above which velocimetry was considered normal and below which it was considered abnormal, according to reference values of D Gramellini et al.

\section{Statistical Methods}

The diagnostic statistics were used to find the diagnostic value of Umb A PI, MCA PI in relation to perinatal outcome.

The sensitivity, specificity, positive predictive value, negative predictive value and diagnostic accuracy were determined for all Doppler measurements using formulas

Statistical software:

Microsoft Word and Excel have been used to generate graphs, tables etc.

SSPS 20 was used for statistical analysis.

\section{Results}

Prospective study of 90 antenatal patients was done after considering the inclusion and exclusion criteria.

Out of these 90 patients 44 patients were considered for subsequent follow up out of which 23 patients were again followed up. Total ultrasound examination done were 156 in span of thesis study in 90 patients out of which 36 examination were between 26-30 weeks and 120 examination between 31-36 weeks, accordingly Flow velocity waveforms of the uterine, umbilical, middle cerebral artery \& ductus venosus were obtained from all 156 total examination in 90 patients and analyzed.

\section{Distribution of Age of the Patients}

Table1. Distribution of age of patients

\begin{tabular}{|l|l|}
\hline Age In Years & Number \\
\hline$<20$ & 1 \\
\hline $20-25$ & 56 \\
\hline $26-30$ & 30 \\
\hline$>30$ & 2 \\
\hline Total & $\mathbf{9 0}$ \\
\hline
\end{tabular}

All our patients ranged from 18 years to 35 years. Majority of the patients 56 were in 20-25 years age group. 30 were between 25-30 years and 2 patients were $>30$ years and only 1 patient was $<18$ years.

Graph1. Showing the distribution of age of patients

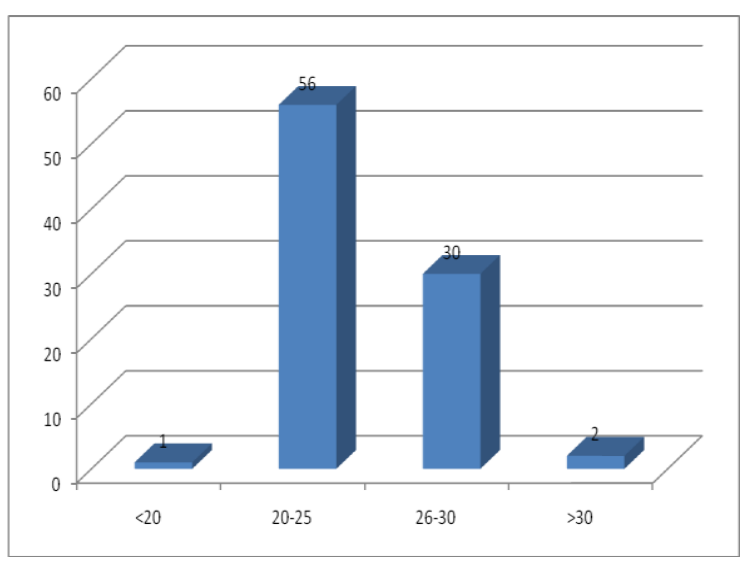

\section{Distribution of Doppler Examinations Done in Gestational Age}

In our study, total 156 examinations were done in 90 patients range between 24-36 weeks

Table2. Distribution of Doppler Examinations done in Gestational Age between 24-36 Weeks

\begin{tabular}{|c|c|}
\hline $24-30$ weeks & 36 \\
\hline $31-36$ weeks & 120 \\
\hline total & 156 \\
\hline
\end{tabular}

36 examinations were done between 24-30 weeks and 120 examination done between 31 36 weeks in total 150 examinations done in 90 patients.

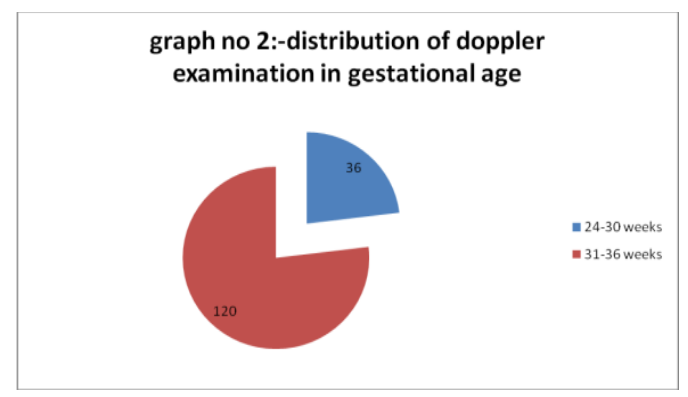

Distribution of Clinical Presentation in 90 Antenatal Patients

In study group of 90 antenatal patients,data for clinical presentation shown below

Table3. Clinical Presentation in 90 Antenatal Patients

\begin{tabular}{|c|c|}
\hline No illness & 51 \\
\hline Hypertension & 28 \\
\hline Anemia & 3 \\
\hline Hypertension+ anemia & 2 \\
\hline Bod & 5 \\
\hline Hypertension+bod & 1 \\
\hline TOTAL & $\mathbf{9 0}$ \\
\hline
\end{tabular}

Out of 90 patients indicated for Doppler ultrasound 28 had pregnancy induced 
hypertension 3 patients had anemia only, 2 patients had both pregnancy induced hypertension and anaemia, 5 patients had bad obstretic history and 1 patient had both pregnancy induced hypertension and bad obstretic history, rest 51 indicated for Doppler ultrasound had no illness

Graph3. Distribution of Clinical Presentation in 90 Patients

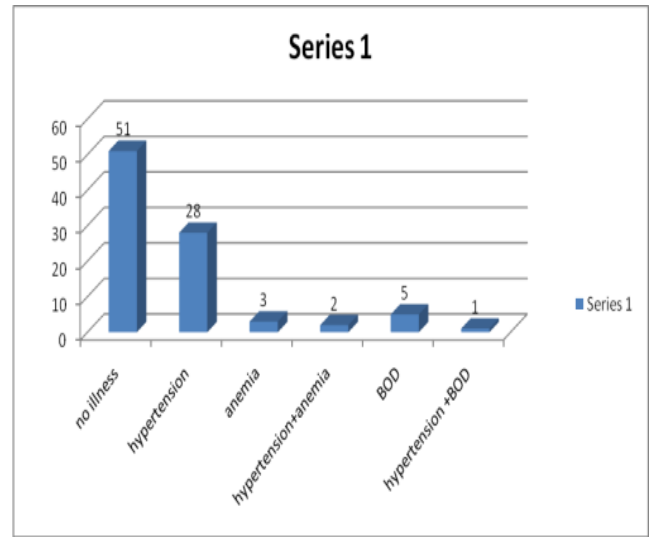

Distribution of Amniotic Fluid Volume

Table4. Showing the Distribution of Amniotic Fluid Volume in 90 Patients

\begin{tabular}{|c|c|}
\hline Amniotic Fuild Volume & Number \\
\hline Normal & 65 \\
\hline Reduced & 25 \\
\hline Total & $\mathbf{9 0}$ \\
\hline
\end{tabular}

Among 90 patients examined, 25 patients had reduced amniotic fluid volume and 65 had adequate amniotic fluid volume

Graph4. Showing the Disribution of Amniotic Fluid Volume in 90 Patients

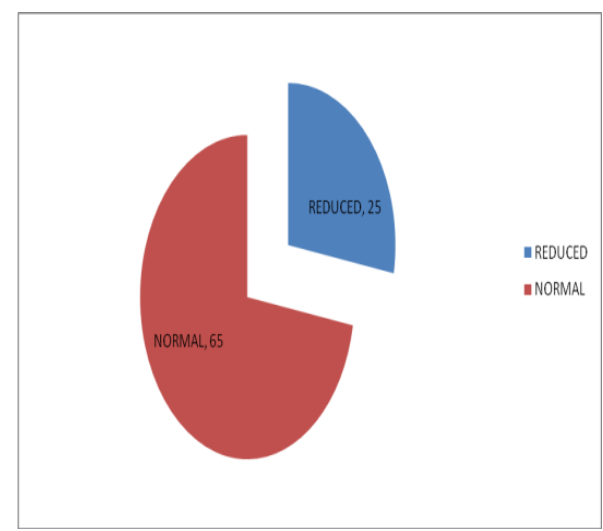

Data Was Analyzed Taking 156 Examination in Consideration done in 90 Patients in Study Time.

(A) In between 24-30 Weeks 36 Examinations were done

1. Uterine Artery Doppler Studies

a. Changes In Ri and Pi Value Changes
Table5. Changes in Right and Left Uterine Artery RI and PI Value

\begin{tabular}{|c|c|c|c|c|}
\hline & $\begin{array}{c}\text { Right } \\
\text { Uterine } \\
\text { A RI }\end{array}$ & $\begin{array}{c}\text { Right } \\
\text { Uterine } \\
\text { A PI }\end{array}$ & $\begin{array}{c}\text { Left } \\
\text { Uterine } \\
\text { A RI }\end{array}$ & $\begin{array}{c}\text { Right } \\
\text { Uterine } \\
\text { PI }\end{array}$ \\
\hline Elevated & 17 & 11 & 15 & 10 \\
\hline Normal & 19 & 25 & 21 & 26 \\
\hline TOTAL & $\mathbf{3 6}$ & $\mathbf{3 6}$ & $\mathbf{3 6}$ & $\mathbf{3 6}$ \\
\hline
\end{tabular}

Among 36 examinations done between age 2430 weeks elevated RI and PI in right uterine artery is 17 and 11 and left uterine artery is 15 and 10 respectively and rest showed normal RI and PI values

Graph5. Showing the Changes in Right and Left Uterine Artery Ri and Pi

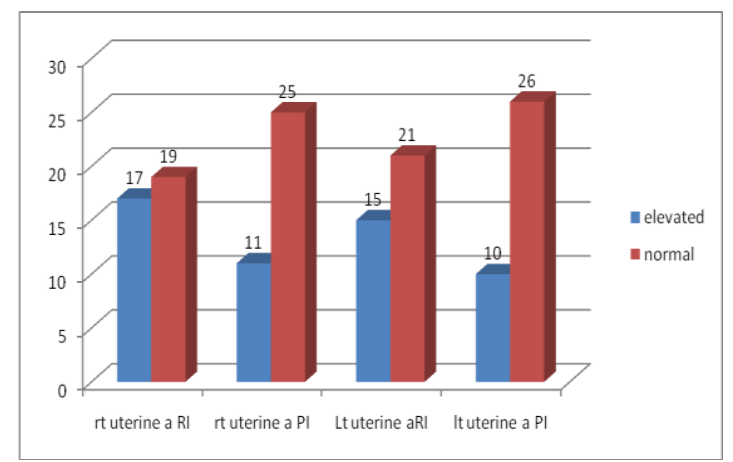

Distribution of Persistant Diastolic Notch in Uterine Arteries

Table6. Showing Distribution of Diastolic Notch in Uterine Arteries

\begin{tabular}{|c|c|c|c|}
\hline $\begin{array}{c}\text { Diastolic } \\
\text { Notch }\end{array}$ & $\begin{array}{c}\text { Right } \\
\text { Uterine A }\end{array}$ & $\begin{array}{c}\text { Left } \\
\text { Uterine A }\end{array}$ & Both \\
\hline Present & 9 & 10 & 05 \\
\hline Absent & 27 & 26 & 31 \\
\hline Total & 36 & 36 & 36 \\
\hline
\end{tabular}

Among 36 examinations done 9 had early diastolic notch and 27 had no diastolic notch in right uterine artery, 10 had diastolic notch and 26 had no diastolic notch in left uterine artery and 5 had diastolic notch in both uterine arteries whereas 31 had no both uterine arteries affected.

Graph7. Showing the Distribution of Diastolic Notch in Uterine Arteries

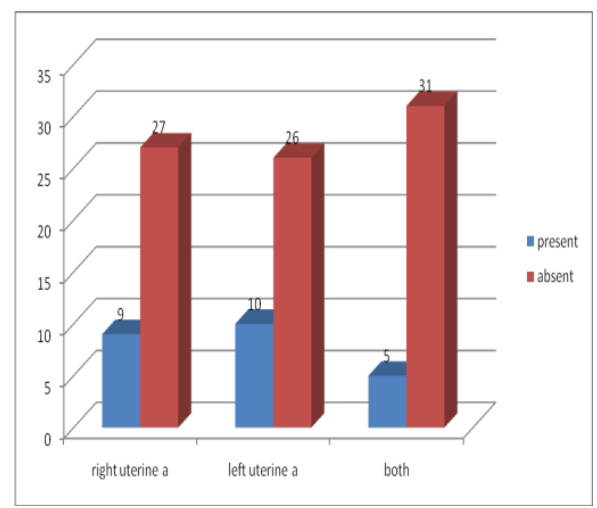


Changes in Uterine Artery Using Ri, Pi, Diastolic Notch Parameters

Table7. Doppler Findings in Uterine Artery Using All Parameters (RI, PI and Diastolic Notch) in Right Uterine Artery

\begin{tabular}{|c|c|c|c|}
\hline $\begin{array}{c}\text { Right Uterine } \\
\text { Artery }\end{array}$ & Present & Absent & Total \\
\hline $\begin{array}{c}\text { Diastolic Notch + } \\
\text { Elevated Ri \& Pi }\end{array}$ & 13 & 23 & 36 \\
\hline $\begin{array}{c}\text { Diastolic Notch+ } \\
\text { Elevated Ri }\end{array}$ & 1 & 35 & 36 \\
\hline $\begin{array}{c}\text { Diastolic Notch + } \\
\text { Elevated Pi }\end{array}$ & 0 & 36 & 36 \\
\hline $\begin{array}{c}\text { Diastolic Notch } \\
\text { Only }\end{array}$ & 0 & 36 & 36 \\
\hline
\end{tabular}

13 had both RI and PI elevated with diastolic notch, 1 had diastolic notch and elevated RI, none had diastolic notch and elevated PI and none had only diastolic notch with normal RI and PI

Graph7. Doppler Findings in Uterine Artery Using All Parameters (RI, PI and Diastolic Notch) in Right Uterine Artery

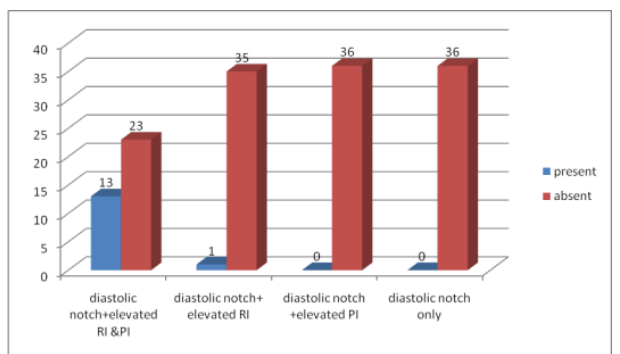

Table8. Doppler Findings in Uterine Artery Using All Parameters (RI,PI And Diastolic Notch) in Left Uterine Artery

\begin{tabular}{|c|c|c|c|}
\hline Left Uterine Artery & Present & Absent & Total \\
\hline $\begin{array}{c}\text { Diastolic Notch + } \\
\text { Elevated Ri \& Pi }\end{array}$ & 9 & 27 & 36 \\
\hline $\begin{array}{c}\text { Diastolic Notch+ } \\
\text { Elevated Ri }\end{array}$ & 1 & 35 & 36 \\
\hline $\begin{array}{c}\text { Diastolic Notch + } \\
\text { Elevated Pi }\end{array}$ & 0 & 36 & 36 \\
\hline Diastolic Notch Only & 0 & 36 & 36 \\
\hline
\end{tabular}

9 had both RI and PI elevated with diastolic notch, 1 had diastolic notch and elevated RI ,none had diastolic notch and elevated PI and none had only diastolic notch with normal RI and PI

Graph8. Doppler Findings in Uterine Artery Using All Parameters (RI,PI and Diastolic Notch) in Left Uterine Artery

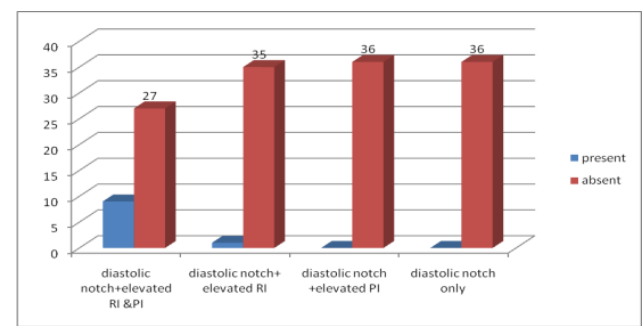

ARC Journal of Gynecology and Obstetrics
2. Umbilical Artery Doppler Studies

a. Umbilical Artery Pulsatility Index and S/D Ratio

Table9. Findings of Umbilical Artery Doppler Examination

\begin{tabular}{|c|c|c|c|}
\hline Umbilcal Artery & Elevated & Normal & Total \\
\hline $\mathrm{Pi}$ & 3 & 33 & 36 \\
\hline S/D Ratio & 3 & 33 & 36 \\
\hline
\end{tabular}

Out of 36 examinations 3 had elevated and 33 had normal UMA PI and 3 had elevated and 33 had normal S/D ratio

Graph9. FindingsoOf Umbilical Artery Doppler Examination

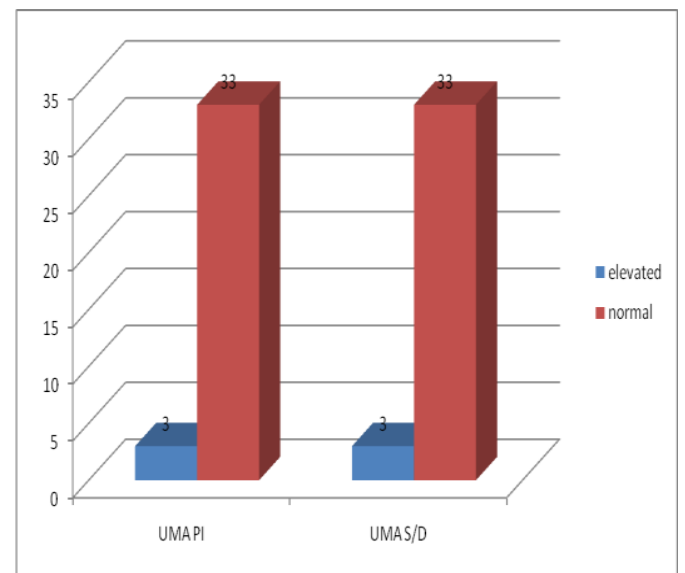

b. Umbilical Artery End Diastolic Velocity Flow Pattern

Table10. Showing Patterns of Umbilical Artery End Diastolic Velocity Flow Pattern

\begin{tabular}{|c|c|}
\hline End Diastolic Flow Pattern & Number \\
\hline Positive Diastolic Flow & 33 \\
\hline Reduced & 3 \\
\hline Absent & 0 \\
\hline Reversed & 0 \\
\hline Total & $\mathbf{3 6}$ \\
\hline
\end{tabular}

In between 24-30 weeks, among total 36 examinations done 3 has reduced end diastolic flow velocity where as 33 had positive diastolic flow velocity pattern. And none had absent or reversed diastolic flow velocity pattern

Graph10. Patterns of End Diastolic Flow in Umbilical Artery

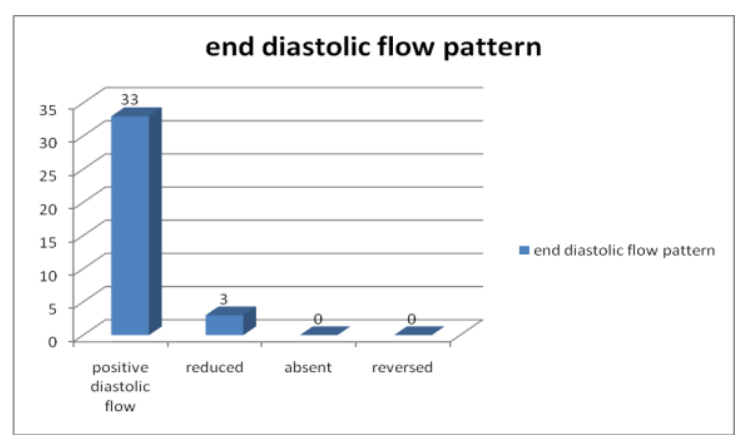




\section{Analysis of both Umbilical and Uterine Artery}

Table11. Analysis of both Umbilical and Uterine Artery

\begin{tabular}{|c|c|}
\hline $\begin{array}{c}\text { Both Uterine Artery \&Umbilical Artery } \\
\text { Changes }\end{array}$ & 3 \\
\hline Only Uterine Artery Changes & 16 \\
\hline Only Umbilical Artery Changes & 1 \\
\hline Both Normal & 16 \\
\hline
\end{tabular}

Out of 36 examinations between 24-30 weeks, 3 had abnormal changes in both uterine and UMA 16 had only abnormal uterine artery changes and 1 had only abnormal UMA changes whereas 16 had normal uterine and UMA changes.

Graph11. Analysis of both Umbilical Artery and Uterine Artery

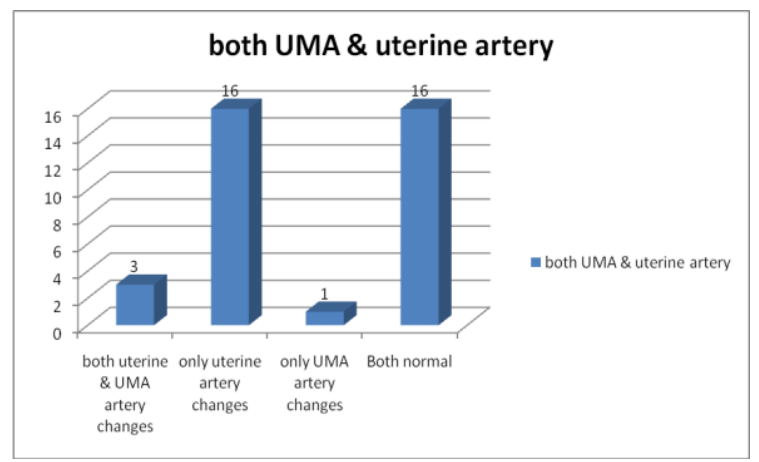

\section{Fetal Middle Cerebral Artery Doppler Changes}

Table12. Fetal middle cerebral artery pulsatility index and $S / D$ ratio changes

\begin{tabular}{|c|c|c|}
\hline Mca & Decreased & Normal \\
\hline $\mathrm{Pi}$ & 3 & 30 \\
\hline $\mathrm{S} / \mathrm{D}$ & 8 & 28 \\
\hline
\end{tabular}

3 had decreased MCA PI and 8 had decreased S/D ratio whear as 20 had normal MCA PI and 28 had normal S/D ratio in total 36 examinations done

Graph12. Changes in Fetal MCA PI and S/D Ratio

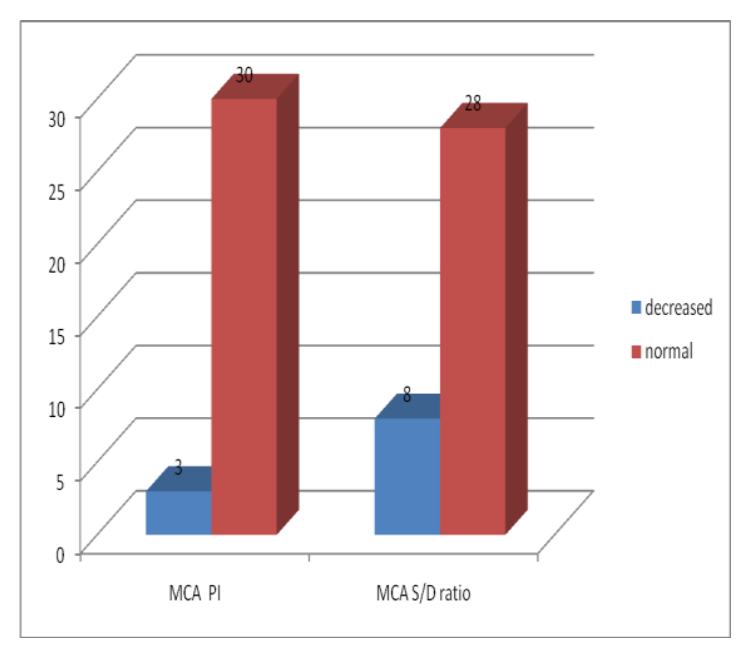

ARC Journal of Gynecology and Obstetrics

\section{Fetal Ductus Venosus Flow Pattern}

Table13. Showing Changes in Ductus Venosus "A Wave" Flow Pattern

\begin{tabular}{|c|c|}
\hline Pattern & Number \\
\hline Normal & 35 \\
\hline Reduced & 1 \\
\hline Absent & 0 \\
\hline Reversed & 0 \\
\hline
\end{tabular}

35 had normal ductus venosus flow" a wave" pattern only 1 had reduced and none had absent and reversed ductus venosus a wave values

(B) From 31 -36 Weeks

1. Uterine Artery Doppler Studies

a. Changes in Ri and Pi Value Changes

Table14. Changes in Right and Left Uterine Artery RI and PI Value

\begin{tabular}{|c|c|c|c|c|}
\hline & $\begin{array}{c}\text { Right } \\
\text { uterine } \\
\text { a RI }\end{array}$ & $\begin{array}{c}\text { Right } \\
\text { uterine } \\
\text { a PI }\end{array}$ & $\begin{array}{c}\text { Left } \\
\text { uterine } \\
\text { a RI }\end{array}$ & $\begin{array}{c}\text { Left } \\
\text { uterine } \\
\text { a PI }\end{array}$ \\
\hline Elevated & 15 & 13 & 16 & 15 \\
\hline Normal & 105 & 107 & 104 & 105 \\
\hline Total & 120 & 120 & 120 & 120 \\
\hline
\end{tabular}

Among 120 examinations done between age 3136 weeks elevated RI and PI in right uterine artery is 15 and 13 and left uterine artery is 16 and 15 respectively and rest showed normal RI and PI values

Graph13. Changes in Right and Left Uterine Artery RI and PI

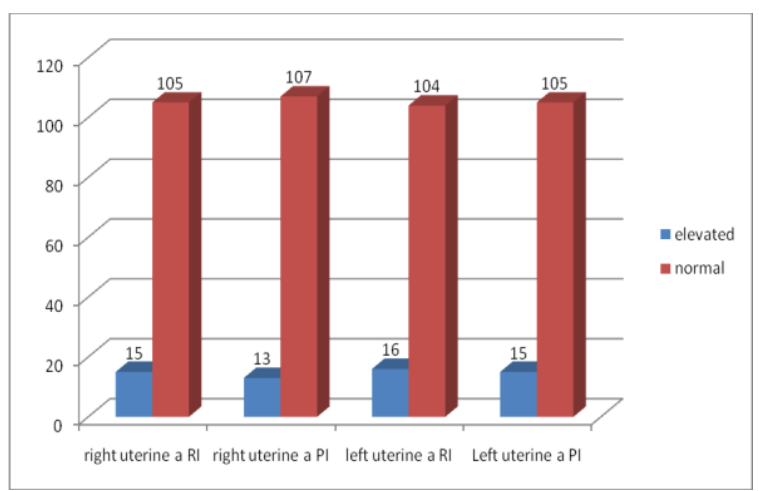

b. Distribution of Persistant Diastolic Notch in Uterine Arteries

Table15. Showing Distribution of Diastolic Notch in Uterine Arteries

\begin{tabular}{|c|c|c|c|}
\hline $\begin{array}{c}\text { Diastolic } \\
\text { Notch }\end{array}$ & $\begin{array}{c}\text { Right } \\
\text { Uterine A }\end{array}$ & $\begin{array}{c}\text { Left } \\
\text { Uterine A }\end{array}$ & Both \\
\hline Present & 16 & 13 & 6 \\
\hline Absent & 104 & 107 & 114 \\
\hline Total & 120 & 120 & 120 \\
\hline
\end{tabular}

Among 120 examinations done 16 had early diastolic notch and 104 had no diastolic notch in right uterine artery, 13 had diastolic notch and 
107 had no diastolic notch in left uterine artery and 6 had diastolic notch in both uterine arteries whereas 114 had no both uterine arteries affected

Graph14. Showing Distribution of Diastolic Notch in Uterine Arteries

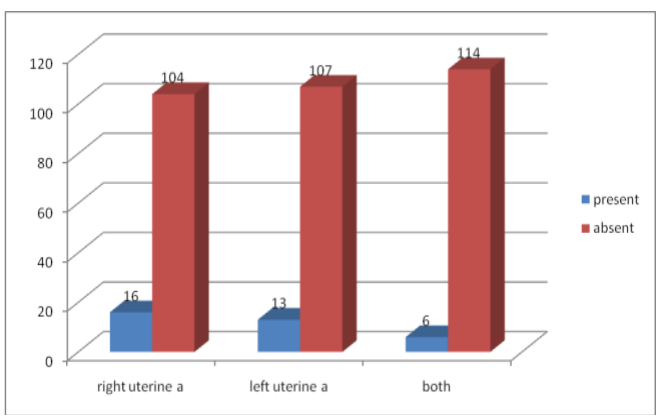

c. Changes in Uterine Artery Using Ri, Pi, Diastolic Notch Parameters

Table16. Doppler Findings in Uterine Artery Using All Parameters (RI, PI and Diastolic Notch) in Right Uterine Artery

\begin{tabular}{|c|c|c|}
\hline Right Uterine Artery & Present & Absent \\
\hline $\begin{array}{c}\text { Diastolic notch + elevated RI } \\
\text { \& PI }\end{array}$ & 10 & 110 \\
\hline Diastolic notch+ elevated RI & 2 & 118 \\
\hline Diastolic notch + elevated PI & 1 & 119 \\
\hline Diastolic notch only & 2 & 118 \\
\hline
\end{tabular}

10 had both RI and PI elevated with diastolic notch, 2 had diastolic notch and elevated RI, 1 had diastolic notch and elevated PI and 2 had only diastolic notch with normal RI and PI

Graph15. Doppler Findings in Right Uterine Artery Using All Parameters

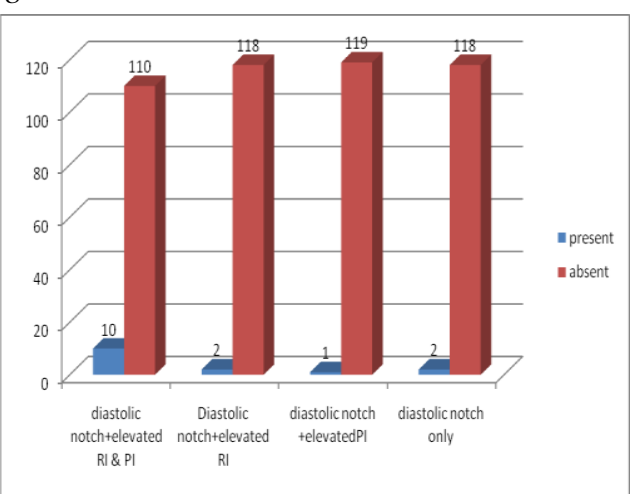

Table17. Doppler Findings in Uterine Artery Using All Parameters (RI, PI and Diastolic Notch) in Left Uterine Artery

\begin{tabular}{|c|c|c|}
\hline Left Uterine Artery & Present & Absent \\
\hline $\begin{array}{c}\text { Diastolic Notch + Elevated Ri } \\
\text { \& Pi }\end{array}$ & 9 & 111 \\
\hline Diastolic Notch+ Elevated Ri & 0 & 120 \\
\hline Diastolic Notch + Elevated Pi & 4 & 116 \\
\hline Diastolic Notch Only & 0 & 120 \\
\hline
\end{tabular}

9 had both RI and PI elevated with diastolic notch, none had diastolic notch and elevated RI , 4 had diastolic notch and elevated PI and none had only diastolic notch with normal RI and PI
Graph16. Doppler Findings in Uterine Artery Using All Parameters (RI, PI and Diastolic Notch) in Left Uterine Artery

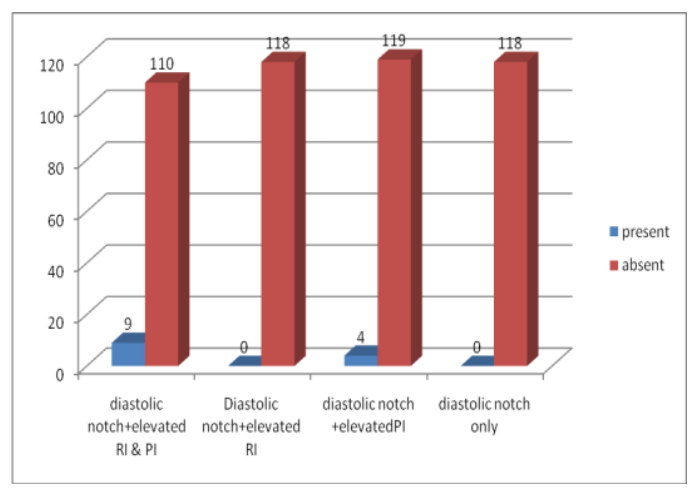

\section{Umbilical Artery Doppler Studies}

a. Umbilical Artery Pulsatility Index Aand S/D Ratio

Table18. Findings of Umbilical Artery Doppler Examination

\begin{tabular}{|c|c|c|}
\hline Umbilcal Artery & Elevated & Normal \\
\hline Pi & 21 & 99 \\
\hline S/D Ratio & 22 & 98 \\
\hline
\end{tabular}

Out of 120 examinations 21 had elevated and 99 had normal UMA PI and 22 had elevated and 98 had normal S/D ratio

Graph17. Findings of Umbilical Artery Doppler Examination

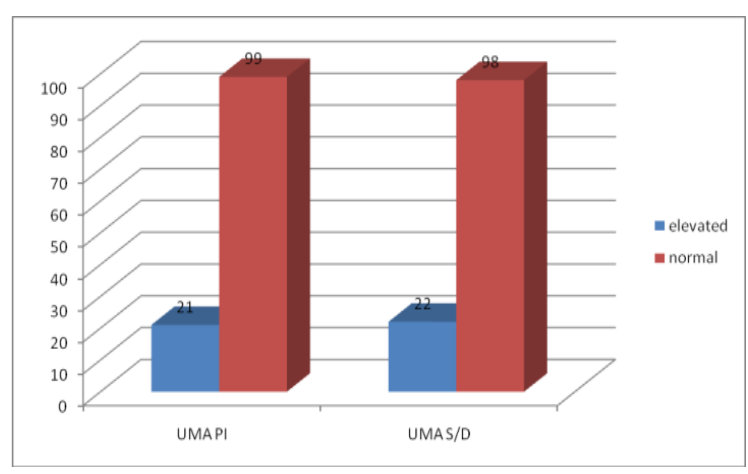

\section{Umbilical Artery End Diastolic Velocity} Flow Pattern

Table19. Distribution of End Diastolic Flow Patterns in Umbilical Artery

\begin{tabular}{|c|c|}
\hline End Diastolic Flow Pattern & NUMBER \\
\hline Positive Diastolic Flow & 103 \\
\hline Reduced & 14 \\
\hline Absent & 2 \\
\hline Reversed & 1 \\
\hline TOTAL & $\mathbf{1 2 0}$ \\
\hline
\end{tabular}

In between 31-36 weeks, among total 120 examinations done 103 had positive diastolic flow pattern, 14 had reduced and 2 had absent and 1 had reversed end diastolic flow patterns. 
Graph18. Showing the Distribution of Patterns of End Diastolic Flow in Umbilical Artery

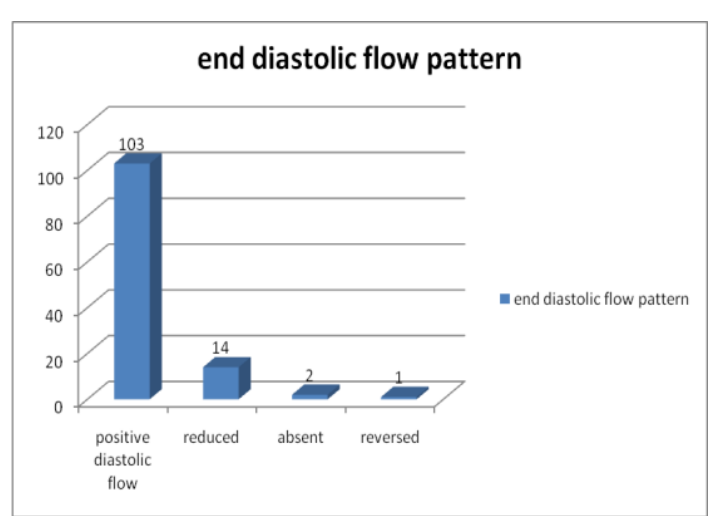

4. Analysis of both Umbilical and Uterine Artery

Table20. Analysis of both Umbilical and Uterine Artery

\begin{tabular}{|c|c|}
\hline $\begin{array}{c}\text { Both Uterine Artery \&Umbilical Artery } \\
\text { Changes }\end{array}$ & 9 \\
\hline Only Uterine Artery Changes & 13 \\
\hline Only Umbilical Artery Changes & 11 \\
\hline Both Normal & 87 \\
\hline
\end{tabular}

Out of 36 examinations between 24-30 weeks, 3 had abnormal changes in both uterine and UMA 16 had only abnormal uterine artery changes and 1 had only abnormal UMA changes whereas 16 had normal uterine and UMA changes.

Graph19. Analysis of both Umbilical Artery and Uterine Artery

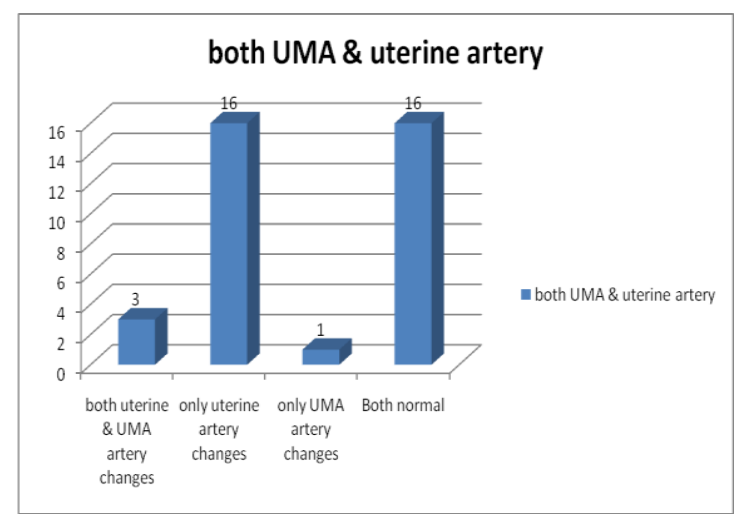

\section{Fetal Middle Cerebral Artery Doppler Changes}

Table21. Fetal Middle Cerebral Artery Pulsatility Index and S/D Ratio Changes

\begin{tabular}{|c|c|c|}
\hline Mca & Decreased & Normal \\
\hline $\mathrm{Pi}$ & 44 & 76 \\
\hline $\mathrm{S} / \mathrm{D}$ & 45 & 75 \\
\hline
\end{tabular}

44 had decreased MCA PI and 45 had decreased S/D ratio whearas 76 had normal MCA PI and75 had normal S/D ratio in total 36 examinations done
Graph20. Changes in Fetal MCA PI and S/D Ratio

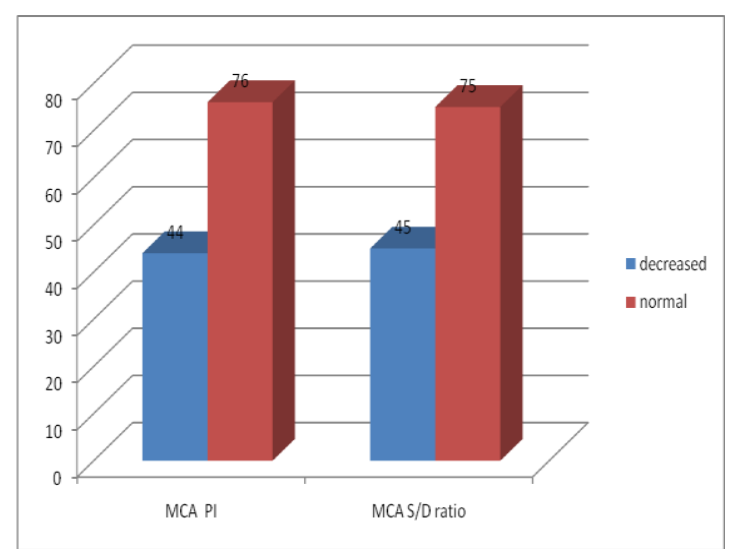

\section{Fetal Ductus Venosus Flow Pattern}

Table22. Showing Changes in Ductus Venosus "A Wave" Flow Pattern

\begin{tabular}{|c|c|}
\hline Pattern & Number \\
\hline Normal & 117 \\
\hline Reduced & 1 \\
\hline Absent & 1 \\
\hline Reversed & 1 \\
\hline
\end{tabular}

117 had normal ductus venosus flow" a wave" pattern, 1 had reduced, 1 had absent and 1 had reversed ductus venosus a wave values.

Table23. Showing Performance Characteristics of Doppler Indices between 24-30 Weeks

\begin{tabular}{|l|l|}
\hline Elevated right uterine RI & 17 \\
\hline Elevated right uterine PI & 11 \\
\hline Elevated left uterine artery RI & 15 \\
\hline Elevated left uterine artery PI & 10 \\
\hline Right uterine diastolic notch & 9 \\
\hline Left uterine diastolic notch Diastolic & 13 \\
\hline $\begin{array}{l}\text { Right uterine a } \\
\text { notch+elevated RI and PI }\end{array}$ & 13 \\
\hline $\begin{array}{l}\text { Left uterine a diastolic notch + elevated } \\
\text { RI and PI }\end{array}$ & 9 \\
\hline Elevated UMA PI & 3 \\
\hline Elevated UMA S/D ratio & 3 \\
\hline Abnormal end diastolic flow pattern & 3 \\
\hline Abnormal UMA and uterine artery & 3 \\
\hline Abnormal MCA PI & 3 \\
\hline Abnormal MCA S/D & 8 \\
\hline Abnormal ductus venosus a wave & 1 \\
\hline
\end{tabular}

Graph21. Showing Performance characteristics of Doppler indices between 24-30 weeks

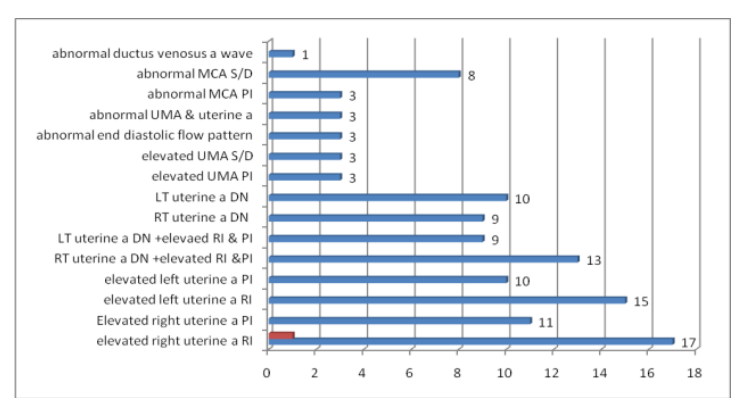


Table24. Showing performance characteristic of Doppler indices between 31-36 weeks

\begin{tabular}{|l|l|}
\hline Elevated right uterine PI & 15 \\
\hline Elevated right uterine RI & 13 \\
\hline Elevated left uterine arteryPI & 16 \\
\hline Elevated left uterine artery RI & 15 \\
\hline Right uterine diastolic notch & 16 \\
\hline Left uterine diastolic notch & 13 \\
\hline $\begin{array}{l}\text { Right uterine a Diastolic } \\
\text { notch+elevated RI and PI }\end{array}$ & 10 \\
\hline $\begin{array}{l}\text { Left uterine a diastolic notch }+ \\
\text { elevated RI and PI }\end{array}$ & 9 \\
\hline Elevated UMA PI & 21 \\
\hline Elevated UMA S/D ratio & 21 \\
\hline $\begin{array}{l}\text { Abnormal end diastolic flow } \\
\text { pattern }\end{array}$ & 17 \\
\hline $\begin{array}{l}\text { Abnormal UMA and uterine } \\
\text { artery }\end{array}$ & 9 \\
\hline Abnormal MCA PI & 44 \\
\hline Abnormal MCA S/D & 45 \\
\hline Abnormal ductus venosus a wave & 3 \\
\hline
\end{tabular}

Graph22. Showing performance characteristic of Doppler indices between 31-36 weeks

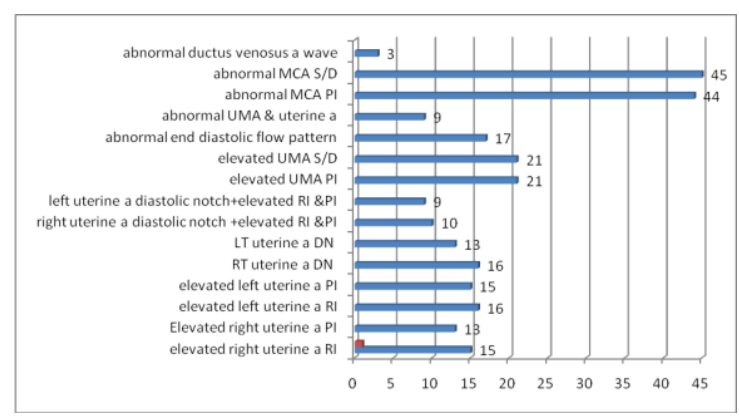

Analysis of Perinatal Outcome

Table25. Showing the analysis of perinatal outcome

\begin{tabular}{|l|l|}
\hline Normal & 62 \\
\hline Adverse & 21 \\
\hline Adverse +death & 7 \\
\hline TOTAL & 90 \\
\hline
\end{tabular}

There were 7 intrauterine deaths and 83 live births. Of these 83 live births 21 had adverse perinatal outcome as 16 had emergency ceasarian section and 5 were submitted to the NICU

Graph23. Analysis of perinatal outcome

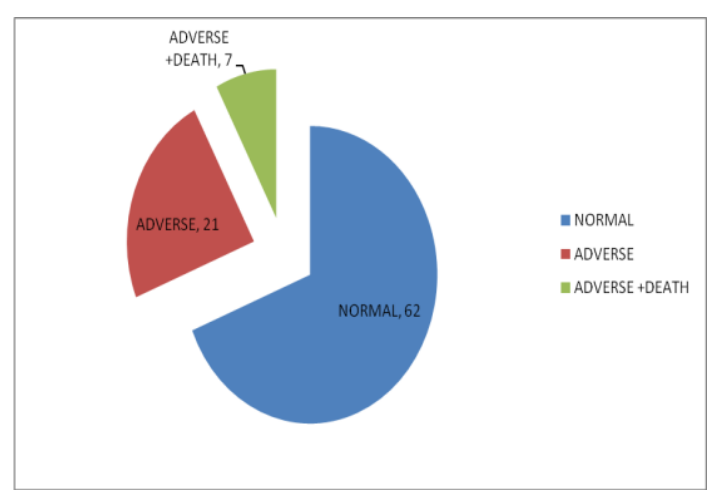

Table26. Showing the distribution of adverse outcomes

\begin{tabular}{|l|l|}
\hline ADVERSE OUTCOME & NO. OF CASES \\
\hline Intrauterine deaths & 7 \\
\hline Admission to NICU & 5 \\
\hline $\begin{array}{l}\text { Emergency Caesarian } \\
\text { section }\end{array}$ & 16 \\
\hline
\end{tabular}

Graph24. Showing the distribution of adverse outcomes

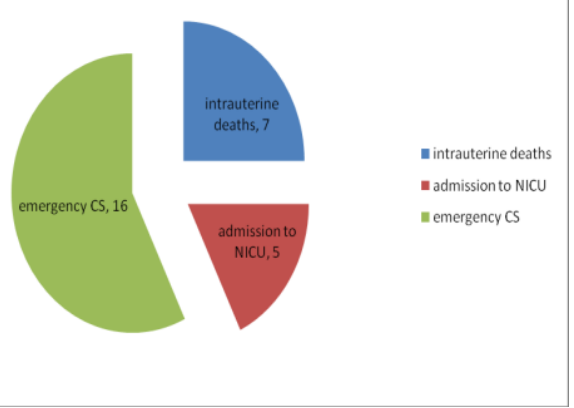

The cuff-off value for Doppler parameters in 28 adverse perinatal outcomes

In uterine artery, RI value at which maximum fetuses had adverse outcome is near $1(>0.7$ abnormal) whereas PI value at which maximum foetuses had adverse perinatal outcome was 1.9 (>1.4 abnormal)

Table no 27 -showing the distribution of UMA PI value in adverse perinatal outcome fetuses

\begin{tabular}{|l|l|}
\hline UMA PI & NUMBER \\
\hline$<1.45$ (NORMAL) & 10 \\
\hline$>1.45$ & 18 \\
\hline TOTAL & 28 \\
\hline
\end{tabular}

18 babies had adverse perinatal outcome when UMA PI value was above 1.45 with maximum adverse outcome at PI value at near 1.6 whereas 10 babies had who had adverse perinatal outcome had PI within normal limits.

Table no 28 -showing the distribution of UMA $S / D$ ratio in adverse erinatal outcome fetuses

\begin{tabular}{|l|l|}
\hline UMA S/D ratio & NUMBER \\
\hline$<3$ & 9 \\
\hline$>3$ & 19 \\
\hline TOTAL & $\mathbf{2 8}$ \\
\hline
\end{tabular}

19 babies had adverse perinatal outcome when UMA S/D ratio value was above 3 with maximum adverse outcome at PI value at near 3.5 whereas 9 babies had who had adverse perinatal outcome had PI within normal limit

Table29. Perinatal outcome $v / s$ UMA reduced labsent/ reversed diastolic flow

\begin{tabular}{|l|l|l|l|l|}
\hline $\begin{array}{l}\text { Diastolic } \\
\text { flow }\end{array}$ & $\begin{array}{l}\text { No. } \\
\text { of } \\
\text { cases }\end{array}$ & $\begin{array}{l}\text { Adverse } \\
\text { outcome }\end{array}$ & Deaths & Mortality \\
\hline Reduced & 17 & 11 & 1 & $5.8 \%$ \\
\hline Absent & 2 & 2 & - & $0 \%$ \\
\hline Reversal & 1 & - & 1 & $100 \%$ \\
\hline
\end{tabular}


Above table shows there 20 fetuses has reduced/absent/reversed diastolic flow in our study. There were 7 deaths in whom 1 had reduced diastolic flow and 1 had reversed diastolic flow.

Table30. Showing the distribution of MCA PI in adverse perinatal outcome fetuses

\begin{tabular}{|l|l|}
\hline MCA PI & NUMBER \\
\hline$<1.2$ & 25 \\
\hline $1.2-1.45$ & 1 \\
\hline$>1.45$ (NORMAL) & 2 \\
\hline TOTAL & 28 \\
\hline
\end{tabular}

25 babies with adverse outcome including the deaths were observed in MCA PI value below 1.2 were as only 2 babies with adverse perinatal outcome had MCA PI above 1.2 but below the normal value for MCA PI $(>1.45)$. And 1 baby

Table32. Showing the Copmparism of Doppler Indices with Adverse Perinatal Outcome

\section{4-30 Weeks-Total 36 Examinations}

\begin{tabular}{|l|l|l|l|l|l|l|l|l|l|}
\hline $\begin{array}{l}\text { DOPPLER } \\
\text { INDEX }\end{array}$ & TP & TN & FP & FN & $\begin{array}{l}\text { SENSI- } \\
\text { TIVITY }\end{array}$ & $\begin{array}{l}\text { SPECI- } \\
\text { FICITY }\end{array}$ & PPV & NPV & $\begin{array}{l}\text { DIAG. } \\
\text { ACCU- } \\
\text { RACY }\end{array}$ \\
\hline $\begin{array}{l}\text { Uterine } \\
\text { artery RI }\end{array}$ & 11 & 12 & 10 & 3 & $78.57 \%$ & $54.54 \%$ & $52.38 \%$ & $80 \%$ & $63.8 \%$ \\
\hline $\begin{array}{l}\text { Uterine } \\
\text { artery PI }\end{array}$ & 12 & 18 & 4 & 2 & $85.71 \%$ & $81.81 \%$ & $75 \%$ & $90 \%$ & $83.33 \%$ \\
\hline $\begin{array}{l}\text { Uterine } \\
\text { artery DN }\end{array}$ & 11 & 20 & 3 & 2 & $84.6 \%$ & $86.95 \%$ & $78.57 \%$ & $90 \%$ & $86 \%$ \\
\hline UMA PI & 11 & 22 & 0 & 3 & $78.57 \%$ & $88 \%$ & $100 \%$ & $88 \%$ & $91.6 \%$ \\
\hline UMA S/D & 11 & 22 & 0 & 3 & $78.57 \%$ & $88 \%$ & $78.5 \%$ & $88 \%$ & $91.6 \%$ \\
\hline MCA PI & 6 & 21 & 2 & 7 & $46.15 \%$ & $91 \%$ & $75 \%$ & $75 \%$ & $75 \%$ \\
\hline MCA S/D & 7 & 21 & 1 & 7 & $50 \%$ & $93 \%$ & $87.5 \%$ & $75 \%$ & $77.77 \%$ \\
\hline
\end{tabular}

Table33.Between 31-36 Weeks-Total 120 Examinations

\begin{tabular}{|l|l|l|l|l|l|l|l|l|l|}
\hline $\begin{array}{l}\text { DOPPLER } \\
\text { INDEX }\end{array}$ & TP & TN & FP & FN & $\begin{array}{l}\text { SENSI- } \\
\text { TIVITY }\end{array}$ & $\begin{array}{l}\text { SPECI- } \\
\text { FICITY }\end{array}$ & PPV & NPV & $\begin{array}{l}\text { DIAG. } \\
\text { ACCU- } \\
\text { RACY }\end{array}$ \\
\hline $\begin{array}{l}\text { Uterine } \\
\text { artery RI }\end{array}$ & 10 & 75 & 12 & 23 & $30.30 \%$ & $86.2 \%$ & $45.45 \%$ & $76.5 \%$ & $70.8 \%$ \\
\hline $\begin{array}{l}\text { Uterine } \\
\text { artery PI }\end{array}$ & 10 & 73 & 16 & 21 & $32.2 \%$ & $84.8 \%$ & $38.4 \%$ & $77.6 \%$ & $70 \%$ \\
\hline $\begin{array}{l}\text { Uterine } \\
\text { artery DN }\end{array}$ & 10 & 76 & 13 & 21 & $32.2 \%$ & $87.3 \%$ & $43.47 \%$ & $84.6 \%$ & $71.6 \%$ \\
\hline UMA PI & 17 & 83 & 5 & 15 & $53.12 \%$ & $94.3 \%$ & $77.2 \%$ & $84.69 \%$ & $83.3 \%$ \\
\hline UMA S/D & 17 & 71 & 7 & 15 & $53.12 \%$ & $91 \%$ & $70.8 \%$ & $82.5 \%$ & $73.3 \%$ \\
\hline MCA PI & 27 & 73 & 17 & 3 & $90 \%$ & $82 \%$ & $61.36 \%$ & $96 \%$ & $84 \%$ \\
\hline MCA S/D & 28 & 73 & 15 & 4 & $87.5 \%$ & $83 \%$ & $65 \%$ & $94.8 \%$ & $84.16 \%$ \\
\hline
\end{tabular}

\section{DISCUSSION}

Fetal growth and development is a natural process for each and every human kind, which has aroused the interests of all clinicians for many years, since not all fetuses grow or develop equally. Intrauterine growth restriction does not imply a specific pathophysiology but merely a result of a series of events occurring along several possible pathways. Hence, had adverse outcome though MCA PI was normal.

Table31. Showing the distribution of MCA S/D ratio value in adverse perinatal outcome fetuses

\begin{tabular}{|l|l|}
\hline MCA S/D ratio & Number \\
\hline $2-2.5$ & 16 \\
\hline $2.5-3$ & 8 \\
\hline$>3$ (NORMAL) & 4 \\
\hline
\end{tabular}

16 babies with adverse outcome including the deaths were observed in MCA S/D ratio value between 2-2.5 maximum at value of 2.2 whereas 8 babies with adverse perinatal outcome had MCA S/D ratio between 2.5-3 and 4 babies born with adverse perinatal outcome has normal MCA S/D ratio. accurate antenatal diagnosis must decide whether the fetus is constitutionally small for gestational age or small as a consequence of impaired placental perfusion. Doppler flow velocity analysis can be valuable in solving this problem, by examining uterine arteries (uteroplacental circulation), umbilical arteries (Feto-placental circulation) and middle cerebral artery (fetal-circulation). 
Our study was done in 90 pregnant women, who were diagnosed as having fetuses with intrauterine growth restriction based on clinical suspicion and grey scale ultrasound examination. Numerous studies with varying results have been published and difficult to compare. This controversy can partly be explained by small number of patients enrolled, varying sample sizes and techniques as well as different criteria used to define the adverse perinatal outcome. In addition some studies were performed in high risk and some in low risk population, similarly major and minor perinatal outcome.

As can be seen yet no universally accepted standard for defining an abnormal Doppler flow velocity waveforms as well as the pregnancy outcome measure, so conflicting observations might continue to emerge.

\section{Age Incidence}

It is observed that the maximum number of pregnant women were in the age group of 21-25 years. This can be attributed probably for the increased pregnancy rate in these age groups. $\mathrm{PIH}$ is more common in primigravida due to first time exposure to chorionic villi.

\section{Distribution of Gestational Age}

In this study all patients underwent Doppler study ranging from 24 weeks to 36 weeks onwards till the termination of pregnancy. Total 156 examinations were done among which 120 examinations were between 31-36 weeks.

The earliest study was done at 24th week of gestation. Hence most pregnancies were monitored between 31-36weeks, when the fetus would have begun developing sufficient lung maturity to survive outside the uterus. Symmetrical IUGR accounts for $20-30 \%$ and asymmetrical IUGR accounts for $70-80 \%$. In asymmetrical IUGR insult begins later than symmetrical IUGR, usually after 28 weeks of gestation. Hence 31-35 weeks of gestation probably could be more common.

\section{Distribution of Clinical Presentation in 90 Antenatal Patients}

Among women where a cause for IUGR was identified. 28 had pregnancy induced hypertension (PIH), 3 had anemia complicating pregnancy. This can be attributed to asymetrical IUGR which accounts for $70-80 \%$ in which uteroplacental insufficiency (PIH) was the most common cause. Hypertensive disorders are present in $30 \%$ to $40 \%$ of pregnancies complicated with IUGR. Bad obstetric history as a cause is seen in 5 patients, 3 had pregnancy induced hypertension with anemia and only 1 had PIH with bad obstretic history. 51 patients of the study group had no detectable cause for IUGR.

\section{Distribution of Amniotic Fluid in 90} Antenatal Patients

\section{Uterine Artery}

Total 150 examinations were done between 2436 weeks in 90 patients 36 examinations were between 24-30 weeks and 120 examinations between 31-36 weeks.

The sensitivity of RI was $78.57 \%$ in our study between 24-30 weeks and sensitivity of RI between 31-36 weeks was 30.3\% which showed uterine artery to be a better predicter of intrauterine fetal growth restriction in earlier periods of gestation than later weeks of pregnancy because of pregnancy induced hypertension which starts developing after 24 weeks and maximum examinations which had abnormal RI in between 24-30 weeks on follow up improved with time. In comparison with that of Benson and Doubliet 73 which had overall $67 \%$ sensitivity between $24-36$ weeks which is less than the sensitivity we found in our study between 24-30 weeks. This discripency may be contributed to different cut of levels of resistive index, varying between 0.5 to 0.7 . Best screening test is measuring placental site uterine artery RI. If the placenta is situated at the midline, the highest RI is best predictor.

The following compares the results of the present study with other studies:

\section{Uterine Artery RI in Predicting Perinatal Outcome}

\section{Study Sensitivity}

Benson and Doubliet75 67\%

Present study*

24-30weeks-78.57\%

31-36weeks-30.3\%

\section{Uterine Artery PI in Predicting Perinatal Outcome}

Jamal A and co-workers ${ }^{79}-61.23 \%$

Present study*

\section{4-30 weeks- $85.71 \%$}

\section{1-36 weeks-31.2\%}

In our present study sensitivity of uterine artery PI was $85.71 \%$ and between $31-36$ weeks was $31.2 \%$ which is more than previous study done.

Hence, present study concludes uterine artery PI to be a better predicter and more significant than uterine artery RI in early weeks of gestation in 
intrauterine fetal growth assesement and in predicting perinatal outcome.

In the present study, the persistent early diastolic notch beyond 24 weeks of gestation showed a sensitivity of $84.6 \%$. This is much higher than the study by Colemann et al 74 who showed sensitivity of the uterine artery notch as $76 \%$ for adverse perinatal outcome. This may be because of the included women was with bilateral notches in Colemann study, whereas in present study presence of diastolic notch either left or right or both were included. However, the analysis done by Farrell et al 75 for reliability of early diastolic notch in uterine artery as predictor for uteroplacental insufficiency revealed a sensitivity of $88 \%$. The following compares the results of the present study with other studies: uterine artery PI appears to be more significantly superior than other parameters

\section{Study Sensitivity}

Colemann et al $7476 \%$

Farrell et al $7588 \%$

Present study* 84.6\%-24-30 weeks

However, uterine artery diastolic notch according to our study showed sensitivity of only $32.2 \%$ in study between 31-36 weeks showing very less number of persistence of diastolic notch in later weeks of pregnancy.

There were three cases who had been detected with diastolic notch in early weeks of pregnancy but timely interventional management at that time with bed rest and medications and follow up caused the disappearance of diastolic notch at follow ups and termination of pregnancy was uneventful

\section{Umbilical Artery}

In the present study the umbilical artery PI had a sensitivity of $78.57 \%$ in between $24-30$ weeks and $53.12 \%$ between $31-36$ weeks.

According to D. Gramellini et al 59, the overall sensitivity of PI in the Umbilical artery in predicting perinatal outcome was $64 \%$. Umbilical artery was the main vessel used for monitoring high risk pregnancies. This is because umbilical artery represents fetoplacental system and primarily reflects placental resistence. In present study as there is more number of PIH cases probably this can be attributed for difference in the studies. Another study by K W Fong et al76 showed the sensitivity of PI in the umbilical artery as $58.3 \%$. The following compares the results of the present study with other studies.
Umbilical artery PI in predicting perinatal outcome

\section{Study Sensitivity}

D Gramellini et al $5964 \%$

K W Fong et al $7644.7 \%$

BN Lakhkar et al $7750 \%$

Present study* $78.57 \%$ between $24-30$ weeks

\section{$53.12 \%$ between $31-36$ weeks}

Hence, our study concludes that umbilical artery PI showed more sensitivity in between 24-30 weeks than 31-36 weeks.

In our present study umbilical artery S/D ratio between 24-30 weeks showed sensitivity of $78.57 \%$ and between 31-36 weeks $53.12 \%$ which was similar to the performance of the umbilical artery S/D ratio between 31-36 weeks

\section{Fetal Blood Circulation and Redistribution}

In the present study fetal middle cerebral artery PI had a sensitivity of $46.15 \%$ in between 24 30 weeks of gestation whereas the sensitivity of the middle cerebral artey PI in between the 3136 weeks gestation was found to be $90 \%$. This outstanding performance of the middle cerebral artery PI in between 31-36 weeks of pregnancy is because changes of IUGR in the the artery become prevalent in later weeks of pregnancy as in earliar weeks there is brain sparing effect which protects the fetal brain from the profound effects of hypoxia .

In Arduini and Rizzo78 study the sensitivity of MCA in predicting perinatal outcome was $68 \%$.

Obviously the present study cannot be compared with the above study in view of difference in considering the intra cranial artery as it is clearly established that PI varies in relation to the intra cranial artery considered. So it is important that the artery be identified precisely and with certainty. 70 The following compares the results of the present study with other studies:

\section{Middle Cerebral Artery PI in Predicting Perinatal Outcome}

\section{Study Sensitivity}

K.W Fong et al76 72.4\%

Arduini and Rizzo78 68\%

BN Lakhkar et al $7741.6 \%$

Present study- 24-30 WEEKS- 46.15\%

\section{1-36 WEEKS-90\%}

\section{Prediction of Perinatal Outcome}

Among those 28 fetuses there were 7 Intra uterine deaths and 21 live births. Out of 21 live births 5 were admitted to NICU, 16 were born 
by emergency caesarian section. These results are slightly higher Gramellini et al59 This can be contributed to difference in perinatal mortality and mobidity rates from western standards to Indian standards. By using Doppler ultrasound results for analysis, the MCA pulsatility index had a higher sensitivity and positive predictive value for predicting the adverse perinatal outcome than the Umb A pulsatility indices and uterine artery PI

Our findings agree with the results of the studies that have shown MCA PI Doppler to be more useful than UmA PI or uterine artery in predicting the adverse outcome. Comparison between different studies would be meaningful if uniform of standardized criteria were used.

Comparison of Diagnostic Accuracies in those Parameters Showing Highest Sensitivity

\begin{tabular}{|l|l|l|}
\hline WEEKS & $\mathbf{2 4 - 3 0}$ & $\mathbf{3 1 - 3 6}$ \\
\hline $\begin{array}{l}\text { UTERINE } \\
\text { ARTERY PI - }\end{array}$ & $\mathbf{8 3 . 3 3 \%}$ & $\mathbf{7 0 \%}$ \\
\hline MCA PI- & $\mathbf{7 5 \%}$ & $\mathbf{8 4 \%}$ \\
\hline
\end{tabular}

Hence, our study confirmed that the uterine artery PI has the best diagnostic accuracy. In between 24-30 weeks and MCA PI proved to have better diagnostic accuracy between 31-36 weeks.

Cuff-off values were observed for the Doppler parameters below or above which these parmeters were significantly associated with perinatal outcome. In uterine artery, RI value at which maximum fetuses had adverse outcome is near 1(>0.7 abnormal) whereas PI value at which maximum foetuses had adverse perinatal outcome was 1.9 ( >1.4 abnormal). maximum adverse outcome was seen when UMA PI value was found to be near 1.6 ( $>1.45$ abnormal) whereas maximum adverse outcome was seen when UMA S/D ratio value was found to be above 3.5. adverse outcome including the deaths were observed in MCA PI value below 1.2 whereas adverse outcome including deaths were observed in MCA S/D ratio at value below $2.2(<3$ abnormal $)$

\section{CONCLUSION}

The umbilical-placental and cerebral vascular beds are directly involved in the haemodynamic adjustments of fetal growth restriction. A Doppler index that reflects both of these areas can be useful for identifying fetuses with increased placental and/or decreased cerebral resistance.

Assessment of both the uteroplacental circulation and the fetoplacental circulations together is more sensitive to predict to perinatal outcome, than assessment of each alone.

In suspected IUGR, uterine artery PI proved to be a better predicter in early weeks of pregnancy than uterine artery RI and diastolic notch and umbilical artery and middle cerebral artery.

Best results are obtained when we use MCA PI, which is more sensitive in detecting IUGR in later weeks of geatation from 31-36 weeks rather than umbilical artery and uterine artery And the diagnostic accuracy of the middle cerebral artery is maximum between $31-36$ weeks.

Cuff-off values were observed for the Doppler parameters below or above which these parmeters were significantly associated with perinatal outcome. In uterine artery, RI value at which maximum fetuses had adverse outcome is near 1(>0.7 abnormal) where as PI value at which maximum foetuses had adverse perinatal outcome was 1.9 (>1.4 abnormal). Maximum adverse outcome was seen when UMA PI value was found to be near 1.6 (>1.45 abnormal) where as maximum adverse outcome was seen when UMA S/D ratio value was found to be above 3.5. Adverse outcome including the deaths were observed in MCA PI value below 1.2 whereas adverse outcome including deaths were observed in MCA S/D ratio at value below $2.2(<3$ abnormal) presence of reversal of diastolic flow in Umbilical artery is an ominous sign since it carries a grave prognosis and high mortality.

Doppler imaging is of value for monitoring the pregnancy because it can provide indirect evidence of fetal compromise and is known to improve outcomes of high risk pregnancies with Intrauterine growth restriction. Hence Doppler evaluation is complementary to all other surveillance modalities.

\section{REFERENCES}

[1] Lugo G.Cassady. Intrauterine growth retardation clinico pathological findings in 233 conseptive infants. Am J Obstest Gynecol 1971; 109: 615-122.

[2] Galbraith RS, Kershmar EJ, Peircy WN, Low JA. The clinical prediction of intrauterine growth retardation. Am J Obstet Gynecol 1979; 133: 281-286.

[3] Devi PIC, Krishna menon MK, Bhaskar Rao K. Postgratuate obstetrics and gynecology. Orient long man; 3rd Edn 1986: 219

[4] Seeds J.W. Impaired fetal growth: definition and clinical clinical diagnosis Obstet Gynecol 1984; 64: 303-310. 
[5] Sendhi Jain, Manju Puri. Diagnosis of intrauterine growth retardation - A review Obstet and Gynec today 2001; 11: 670-673.

[6] Kok JH, Devi Ouden AL, Verloove-Venhorick SP, Brand R. Outcome of very preterm small for gestational age infants : the first nine years of life. Br J Obstet and Genecol 1989; 105: 162-168.

[7] Neilson JP, Alfirevic Z. Doppler Ultrasound in high risk pregnancies In : Neilson JP, Alfirevic Z. DopJP, Crowther CA, Hudnett CED, Hof meyr GJ, Keirse MJNC, eds Pregnancy and child birth module of the cochrone database of systematic reviews. Available in Cochrone library [data base on disk and CD rom]. Issue 3, Oxford, England: Cochrane collaboration, 1998.

[8] Ven den Wijngard JW, Groenenberg IL, Wladimirolb, JW, et al. Cerebral Doppler ultrasound of the fetus. Br J obstet Gynaecol 1989; 86: 845-849.

[9] Fleischer A, Schuman H, Farmakides G et al. Uterine artery Doppler velocimetry in pregnant women with hypertension. Am j obstet Gynecol 1986; 154: 806-813.

[10] Arduini. D, Rizzo G, Romenini C and Mancuso S. Fetal blood flow velocity wave form as predictors of growth retardation. Obstet Gynecol 1987; 70(1) : 7-10.

[11] Vanden Wijngaard JW, Groenenberg IL, Wladimiroff JW, et al. Cerebral Doppler ultrasound of the fetus. Br J Obstet Gynaecol 1989; 96:845-849.

[12] Arduini D, Rizzo G. Prediction of fetal outcome in small for gestational age fetus: comparison of Doppler measurements obtained from different fetal vessels. J Perinat Med 1992; 20:29-38.

[13] Gramellini D, Folli MC, Raboni S, Vadora E, Merialdi A. Cerebral-umbilical Doppler ratio as a predictor of adverse perinatal outcome. Obstet Gynecol 1992; 79:416-420.

[14] R.A.North, C.Ferrier, D Long, K.Townend, and P.Kincaid Smith. Uterine artery Doppler flow velocity wave forms in the second trimester for the prediction of preeclampsia and fetal growth retardation. Obstet Gynecol 1994; 83: 378-
[15] Harrington K, Carpenter RG, Nguyen M, et al: Changes observed in Doppler studies of the fetal circulation in pregnancies complicated by pre-eclampsia or the delivery of a small-forgestational age baby. I. Cross-sectional analysis. Ultrasound Obstet Gynecol 1995; 6(1):19-28

[16] Chan FY, Pun TC, Lam P, Lam C, Lee CP, Lam YH. Fetal cerebral Doppler as a predictor of perinatal outcome and subsequent neurological handicap. Obstet Gynecol 1996; 87:981-988.

[17] Lakhar BN, Ahamed SA .Doppler Velocimetry of Uterine and Umbilical Arteries during Pregnancy .Ind J Radiol Imag 1999; 9: 3: 119125.

[18] Fong KW, Ohlsson A, Hannah ME, Grisaru S, Kingdom J, Ryan M, et al. Prediction of Perinatal Outcome in Fetuses Suspected to Have Intrauterine Growth Restriction: Doppler US Study of Fetal Cerebral, Renal, and Umbilical Arteries. Radiology 1999; 213:681689.

[19] Sterne G, Shields LE, Dubinsky TJ. Abnormal fetal cerebral and umbilical Doppler measurements in fetuses with intrauterine growth restriction predicts the severity of perinatal morbidity. J Clin Ultrasound. 2001 Mar-Apr; 29(3):146-51.

[20] Justin C. Konje, Stephen C. Bell, David J. Taylor. Abnormal Doppler velocimetry and blood flow volume in the middle cerebral artery in very severe intrauterine growth restriction: is the occurrence of reversal of compensatory flow to late? Br J Obstetrics and Gynecology 2001; 108: 973-979.

[21] Murlidhar V pai. Uterine artery Doppler velocimetry in women with normal pregnancy, PIH and IUGR 2001. OGS and Gynec today; 6(a): 668-670.

[22] BN Lakhkar, KV Rajagopal, PT Gourisankar. Doppler prediction of adverse perinatal outcome in PIH and IUGR. Ind J Radiol Imag 2006 16:1:109-116.

[23] Radhika P, Chandrakanth Shetty, Lavenya Rai. Multivessel foetal Doppler and perinatal outcome in IUGR and severe preeclampsia. Obs \& Gynae today 2006; 11(2): 106-109.

Citation: Som Biswas, Srirupa Biswas. Radiology in Iugr: A Study. ARC Journal of Gynecology and Obstetrics 2017; 2(4):20-34. DOI: dx.doi.org/10.20431/2455-9792.0204005

Copyright: (C) 2017 Authors. This is an open-access article distributed under the terms of the Creative Commons Attribution License, which permits unrestricted use, distribution, and reproduction in any medium, provided the original author and source are credited. 